\title{
Virtual Energy Storage: Converting an AC Drive to a Smart- Load
}

DOI:

10.1109/TEC.2018.2815151

\section{Document Version}

Accepted author manuscript

Link to publication record in Manchester Research Explorer

\section{Citation for published version (APA):}

Carmona Sanchez, J., Barnes, M., \& Apsley, J. (2018). Virtual Energy Storage: Converting an AC Drive to a Smart-Load. IEEE Transactions on Energy Conversion, 33(3), 1342-1353.

https://doi.org/10.1109/TEC.2018.2815151

\section{Published in:}

IEEE Transactions on Energy Conversion

\section{Citing this paper}

Please note that where the full-text provided on Manchester Research Explorer is the Author Accepted Manuscript or Proof version this may differ from the final Published version. If citing, it is advised that you check and use the publisher's definitive version.

\section{General rights}

Copyright and moral rights for the publications made accessible in the Research Explorer are retained by the authors and/or other copyright owners and it is a condition of accessing publications that users recognise and abide by the legal requirements associated with these rights.

\section{Takedown policy}

If you believe that this document breaches copyright please refer to the University of Manchester's Takedown Procedures [http://man.ac.uk/04Y6Bo] or contact uml.scholarlycommunications@manchester.ac.uk providing relevant details, so we can investigate your claim.

\section{OPEN ACCESS}




\title{
Virtual Energy Storage: Converting an AC Drive to a Smart-Load
}

\author{
J. Carmona-Sanchez, M. Barnes, Senior Member, IEEE and J. Apsley, Member, IEEE
}

\begin{abstract}
This paper proposes a new Smart-Load concept using AC drives. The concept is based on a secondary control layer coordinated with the network and the load to provide active power support. The general Smart-Load concept is developed and synthesized for its practical implementation in network power-frequency support applications. A multi power-frequency droop line is proposed. The final idea is applied to a fan load powered by an AC drive based on an induction motor and a two level voltage source converter. Experimental results show that a full power-frequency response can be achieved by the SmartLoad within $2 \mathrm{~s}$ of the network frequency deviation.
\end{abstract}

Index Terms - AC Drives, FPGA, Power-Frequency Support, Smart-Loads, Vector Control.

\begin{tabular}{l|l|l|l}
\multicolumn{3}{c}{ NOTATION } \\
\hline variables & \multicolumn{2}{l}{ subscripts } \\
\hline$f$ & Frequency $(\mathrm{Hz})$ & $\mathrm{g}$ & generator \\
\hline$J$ & Inertia $\left(\mathrm{kgm}^{2}\right)$ & $\mathrm{ge}$ & generator electrical \\
\hline$k$ & Droop factor & $\mathrm{gm}$ & generator mechanical \\
\hline$\eta$ & Efficiency & $\mathrm{m}$ & motor \\
\hline$P$ & Power $(\mathrm{W})$ & $\mathrm{me}$ & motor electrical \\
\hline$p$ & Pole pairs & $\mathrm{mm}$ & motor mechanical \\
\hline$T$ & Torque $(\mathrm{Nm})$ & $\mathrm{ms}$ & motor stator \\
\hline$\omega$ & Angular speed (rad/s) & $\mathrm{n}$ & network \\
\hline \multicolumn{2}{|l|}{} & $\mathrm{t}$ & turbine \\
\hline superscripts & \multicolumn{2}{|l}{} \\
\hline ref & Usual (no fault) operating & ss & Steady-state \\
\cline { 2 - 5 } & condition & $*$ & Desired value \\
\hline
\end{tabular}

\section{INTRODUCTION}

$\mathrm{M}$ ANY network transients are related to active and reactive power imbalances [1][2]. When a power imbalance occurs this is reflected in network frequency deviations from nominal conditions. Under such circumstances, rotating masses of conventional synchronous generators release/ absorb the difference in energy to keep the system balance [3]. However, the replacement of conventional generation by low inertia renewable energy generation has resulted in the reduction of the fault level, stored energy and spare VA rating of the whole electric network, making the system more sensitive to frequency oscillations [4]. Research and development is focusing on the application of energy storage for the mitigation of such problems, however, the high cost of such devices is a hindrance to wide penetration of this

Financial support provided by CONACyT (Mexico) to the first author for his $\mathrm{PhD}$ studies.

The authors are with the School of Electrical and Electronic Engineering, The University of Manchester, Manchester M13 9PL, U.K. (e-mail: carmonaipn@live.com.mx; mike.barnes@manchester.ac.uk; J.Apsley@manchester.ac.uk) technology [5].

In electric power networks (EPNs), node voltages are kept within a small percentage of their nominal values. Hence, from the point of view of Demand-Side-Management (DSM), loads have usually fixed parameters such as impedance and power. Therefore, when the system is under severe contingence, DSM implies shedding of the load [3][6][7].

Some network frequency response mechanisms require a fast response (within seconds) from power reserves for network frequency support [8]. This could be easily covered by many types of load without significantly disturbing their driving process due to inherent presence of thermal or mechanical mases. Loads like heating, refrigerators, freezers and air conditioners are examples [9].

Reference [7] proposes a Smart-Load scheme based on voltage-dependant loads, such as heaters and lighting (e.g. LEDs). To achieve the Smart-Load, a voltage compensator is inserted in series between the supply and the load. By doing this, it is possible to control the voltage and active power of the load, hence contributing to network frequency support; additionally, it is possible to provide local voltage support but not both. Other developments for SmartLoads focus on improving existing load shedding schemes, such as in [10], where noncritical loads are identified and shed at appropriate times in an industrial microgrid to prevent collapse of the system. In [11], GSM communication networks are used in combination with a Smart-Load management system (located at the consumer end) to limit the power flow to the consumer in case of a power shortage condition. Additionally, network frequency support can be achieved by averaging the power of the loads by switching them on/off with appropriate duty cycles [7].

The main loads in EPNs are motors, lighting and electric appliances. The load system is dominated by electric motors which cover about $60-70 \%$ of the total [12] [13]. The electric power network stability is largely impacted by the behaviour of these loads, making them potential candidates for DSM. However, loads driven by electric motors, such as airconditioners, particularly those operated through AC drives, exhibit a constant active power over a wide network voltage and frequency range [14], which limits the possibility of continuous active power control [7]. Hence, until now research on this topic has remained untackled. This paper demonstrates that network power-frequency mitigation can be obtained from $\mathrm{AC}$ drives by the implementation of an advanced load management algorithm. A minimal upgrade of the AC drive control structure is necessary, thus, requiring only a small part of the investment and less hardware and less complexity than for energy storage devices. 
Furthermore, in addition to the technology/methods that allows converting an AC drive to an smart-load for network power-frequency support, there must be the right polices that incentivise consumers for taking part in supporting the grid. Regarding this matter, National Grid (UK) has created a framework called "Power Responsive" to be launched by 2020 [15]. This framework mainly focuses on the management of the demand side response (DSR) for network power-frequency support. This will be achieved by consumers reducing or increasing their demand as required. Under such a framework, consumers will receive financial incentives and lower their bills by intelligent use of energy. Additionally, the required standards need to be developed, or adapted, to set the guidelines to maximize the benefit of the variable power demand and response of the load to changing conditions of the network. This could be similar to the IEC 61850/61499 standards used for control and operation of distributed energy resources [16].

\section{General SMART - LOAD CONCEPT BY USING AC DRIVES}

The AC drive control structure is shown in Fig. 1, which also shows the power flow and system hardware. The AC drive control normally determines the inverter firing signals to set the electromagnetic torque $\left(T_{m e}\right)$ or mechanical speed of the motor $\left(\omega_{m m}\right)$. Smart load functionality would be achieved by the integration of a second outer control layer, which is similar to the control hierarchy already used in AC systems and microgrids. This secondary layer would be a supervisory control structure that could be activated under critical conditions of the system. The outer control structure would monitor the network variables (e.g. voltage, frequency), the load variables (e.g. speed, torque) or both, (Fig. 1), and adjust the desired motor speed or torque to adjust the active power drawn from the network. If an active rectifier is implemented on the AC drive's network side, a certain amount of reactive power could be provided/absorbed by the $\mathrm{AC}$ drive and thus this could be used to provide local AC voltage support at the point of common coupling (PCC) between the network and the AC drive. This might be achieved by a droop control strategy. Due to cost and complexity, AC drives generally implement a passive full wave diode-bridge rectifier to convert the AC voltage to DC voltage. Hence, the following section concentrates only in the explanation of the network frequency support by AC drives.

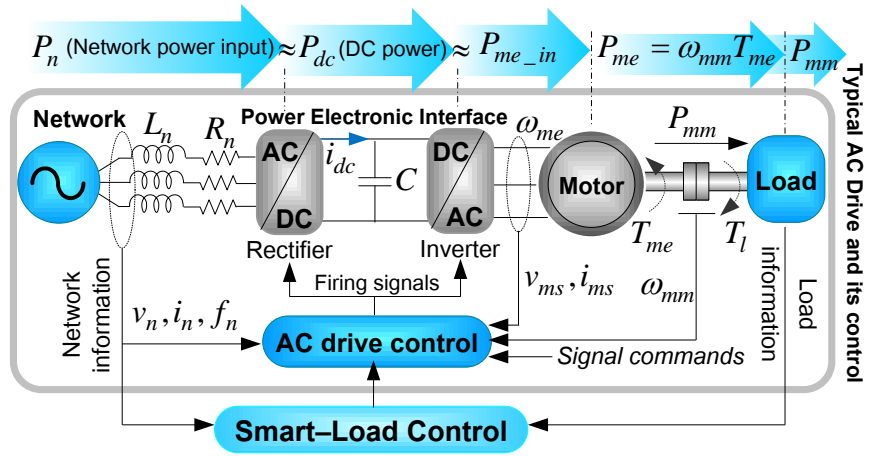

Fig. 1. General AC drive implementation and AC drive Smart-Load concept.

\section{ELECTROMECHANICAL DYNAMICS IN SYNCHRONOUS GENERATORS AND ELECTRIC MOTOR LOADS}

In large EPNs, many synchronous generators are interconnected and all share the same network frequency. The frequency of the electrical network $\left(f_{n}\right)$ is strongly dependent on the power balance between electrical sources and loads and the total system inertia [17]. Fig. 2 represents the electrical network, where, for simplicity, only a single generator and load are shown. The generator-network interface (GNI) is usually a connection transformer. The load-network interface (LNI) may be a soft starter [18], but for this work, only an AC drive will be considered.

The rate of change in mechanical speed $\left(\omega_{g m}\right)$ of a synchronous generator, with inertia $J_{g m}$ (generator rotor plus turbine), as a function of the mechanical $\left(P_{g m}\right)$ and electrical $\left(P_{g e}\right)$ powers is governed by (1) [12][17]; where $T_{t}$ is the turbine mechanical torque and $T_{g e}$ is the generator electromagnetic torque. The actual electric power output ( $P_{\text {ge_out }}$ ) delivered by the generator is given by (2), where $\eta_{g}$ is the generator efficiency. The relation between the stator electric frequency $\left(f_{g e}\right)$, stator electric angular speed $\left(\omega_{g e}\right)$ and the mechanical rotor angular speed is given by (3), where $p_{g}$ represents the number of poles of the generator. This means that a change in generator speed directly changes the network frequency.

$$
\begin{gathered}
\omega_{g m} J_{g m} \frac{d \omega_{g m}}{d t}=\omega_{g m} T_{t}-\underbrace{\omega_{g m} T_{g e}}_{P_{g m}} \\
P_{g e_{-} \text {out }}=\eta_{g} P_{g e} \ldots \ldots \ldots \ldots \ldots \ldots \ldots \ldots \ldots \ldots \ldots \ldots \ldots \ldots \ldots \ldots \ldots \ldots \ldots \ldots \\
f_{g e}=\frac{\omega_{g e}}{2 \pi}=\frac{p_{g}}{4 \pi} \omega_{g m} \ldots \ldots \ldots \ldots \ldots \ldots
\end{gathered}
$$

Similarly, the rate of change in mechanical speed $\left(\omega_{m m}\right)$ of an electric induction motor (IM), with inertia $J_{m m}$ (motor rotor plus load), as a function of the mechanical $\left(P_{m m}\right)$ and electrical $\left(P_{m e}\right)$ power imbalances is governed by (4). In (4), $T_{l}$ is the load mechanical torque, $T_{m e}$ is the motor electromagnetic torque. The relationship between the electric power required to drive the load and the actual input power $\left(P_{m e \_i n}\right)$ to the motor is governed by (5), where $\eta_{m}$ is the motor efficiency. The relation between the IM stator electric angular speed $\left(\omega_{m e}\right)$ and the mechanical rotor angular speed $\left(\omega_{m m}\right)$ is given by (6), where $p_{m}$ represents the number of poles of the IM and $(s)$ is the slip of the machine.

$$
\begin{gathered}
\omega_{m m} J_{m m} \frac{d \omega_{m m}}{d t}=\underbrace{\omega_{m m} T_{m e}}_{P_{m e}}-\omega_{m m} T_{l} . \\
P_{m e}=\eta_{m} P_{m e} i n \\
\omega_{m e}=\frac{1}{(1-s)} \frac{p_{m}}{2} \omega_{m m} \ldots \ldots \ldots \ldots \ldots \ldots \ldots \ldots \ldots \ldots \ldots \ldots \ldots \ldots \ldots \ldots \ldots \ldots \ldots \ldots
\end{gathered}
$$

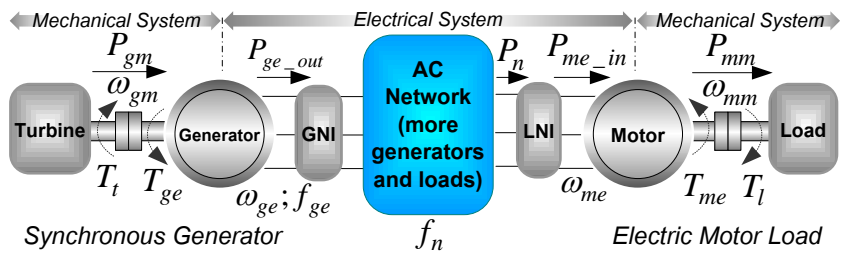

Fig. 2. Synchronous generators and electric motors network connected. 
In normal operation the rotor speed is set to match the requirements of the driven load and is not related to network frequency when operated by an AC drive. However changes in power drawn may indirectly affect the network frequency.

\section{NETWORK POWER-FreQUENCY SUPPORT BY AC DRIVES}

\section{A. Power-Frequency Droop Control for Synchronous Generators and for Electric Motor Loads}

In EPNs, the rate of change of frequency depends on the system inertia and changes in power. To achieve a stable operation of the turbines in synchronous generators, the task of the turbine governor is to adjust the turbine speed. A power-frequency droop characteristic like the ones shown in Fig. 3a and mathematically represented by (7) is generally used, where $f_{n}^{r e f}$ and $P_{g e}^{r e f}$ refer to the frequency $(50 \mathrm{~Hz}$ or $60 \mathrm{~Hz}$ ) and active power references of the generating unit under normal operation conditions. $f_{n}$ is the actual network frequency and $P_{g e}^{*}$ is the desired active power when the network frequency deviates from its reference. The combination of many individual generation units contributes to keep the power-frequency droop factor within a small range (e.g. Fig.3a, slope $k_{g 12}$ ). Such a characteristic defines the ability of the network to compensate for large power imbalances (by making use of spinning reserve) at the cost of small frequency deviations [12].

$$
\Delta f_{n}=f_{n}^{r e f}-f_{n}=-k_{p g}\left(P_{g e}^{r e f}-P_{g e}^{*}\right)
$$

Analogous to the power-frequency droop control in synchronous generators, a similar control can be implemented to AC drives to compensate for network frequency variations. However, in this case the power-frequency droop control must be in load mode (i.e. with a positive slope), Fig. 3b. This allows compatibility with synchronous generators droop control. From (5), the electric motor active power demand $\left(P_{m e_{-} i n}\right)$ can be manipulated by controlling the electric power being converted to mechanical power $\left(P_{m e}\right)$. Hence, considering a lossless power electronic interface the change in active power and network frequency relation for the power electronic interface, can be written as given by (8). Where, $P_{n}^{r e f}$ and $P_{m e_{-} i n}^{r e f}$ are the reference active powers for the AC drive at the network side and for the electric motor, respectively, under normal operation and the $(*)$ denotes the same terms when the network frequency deviates from its reference. From (8), a motor power reference command $\left(P_{m e \_i n}^{*}\right)$ can be generated for the participation of the motor under low network frequency, as given by (9).

$$
\begin{aligned}
& f_{n}^{r e f}-f_{n}=k_{m}\left(P_{n}^{r e f}-P_{n}^{*}\right) \approx k_{m}\left(P_{m e \_i n}^{r e f}-P_{m e_{-} i n}^{*}\right) \ldots \ldots . . . . . \\
& P_{n}^{*}=P_{n}^{r e f}-\frac{f_{n}^{r e f}-f_{n}}{k_{m}} \approx P_{m e_{-} i n}^{*} \approx P_{m e_{-} i n}^{r e f}-\frac{f_{n}^{r e f}-f_{n}}{k_{m}} \ldots \ldots . .
\end{aligned}
$$

The implementation of the power-frequency droop line, in a multi motor-load system can be achieved by following similar procedures as those used for frequency droop control in a multi generator system, this is also shown in Fig. 3b.

\section{B. Multi Power-Frequency Droop Line Approach}

The droop line characteristic, shown in Fig. 3b, only considers the linear impact, of providing network frequency, on the motor input power (demand). The impact on the speed of the driven process (e.g. conveyors, fans, pumps, etc.) also needs to be considered. Therefore, it is desirable to be able to adjust the shape of the droop line considering the load profile as well as to minimize the impact of the network variations on the electric motor driven process. Hence, based on (9), a multi droop line piecewise linear approach is proposed that can be mathematically expressed as given by (10). Equation (10) states the combined effect of two droop factors $k_{p m 1}$ and $k_{p m 2}$. Fig. 4 shows some examples. This equation has been perunitized in terms of power. Hence, to obtain the desired motor power for network frequency support one has to multiply (10) by the power drawn by the motor in normal operating conditions, $P_{m e-i n}^{r e f 0}$, as given by (11). By using (11), the multi power-frequency droop characteristic can be set as desired as shown in Figs. 4a-c. Where $\left(f_{n}^{r e f 0}, P_{m e}^{r e f}{ }_{\text {in }}\right)$ defines the transition from normal operation to frequency support, and the break points $\left(f_{n}^{r e f 1}, P_{m e_{-} i n}^{r e f 1}\right)$ and $\left(f_{n}^{r e f 2}, P_{m e_{-} i n}^{r e f 2}\right)$ define the transition from one droop factor to another.

$$
k_{m}=1-\frac{\left(f_{n}^{r e f 0}-f_{n}^{01}\right)\left(1-p_{1}\right)}{f_{n}^{r e f 0}-f_{n}^{\text {ref } 1}}-\frac{\left(f_{n}^{\text {ref } 1}-f_{n}^{12}\right)\left(p_{1}-p_{2}\right)}{f_{n}^{\text {ref } 1}-f_{n}^{\text {ref } 2}}
$$

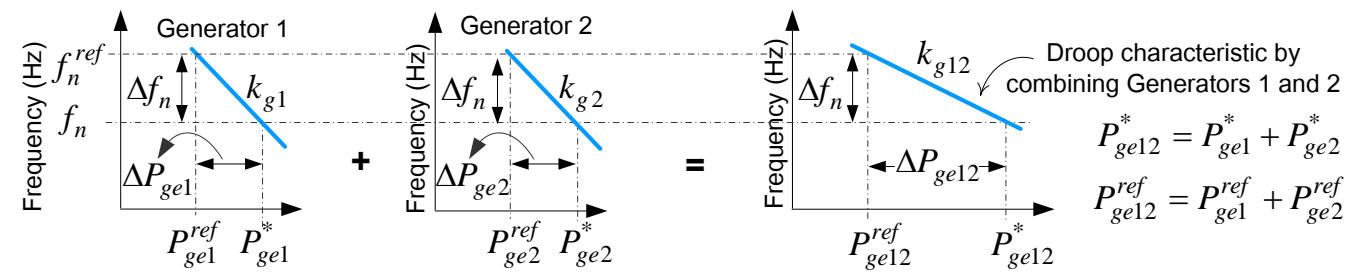

a) Generators droop characteristic

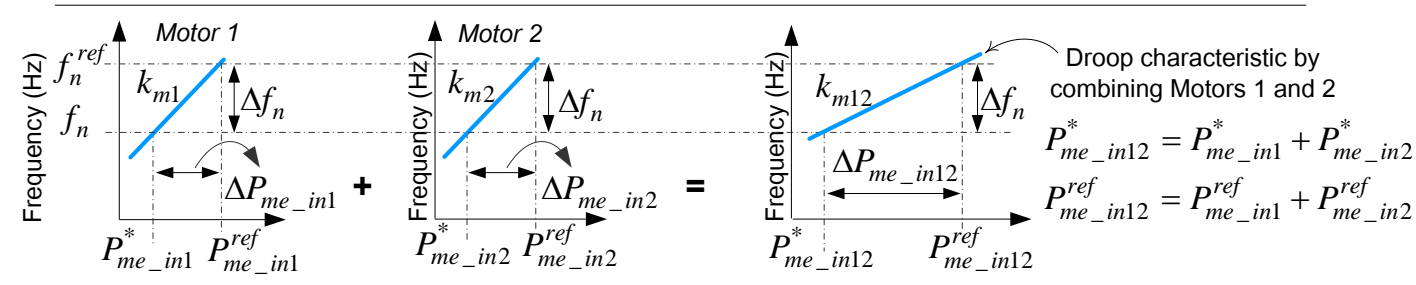

b) Desired load droop characteristic

Fig. 3. Synchronous generators (a) and electric motors (b) desired droop characteristics. 


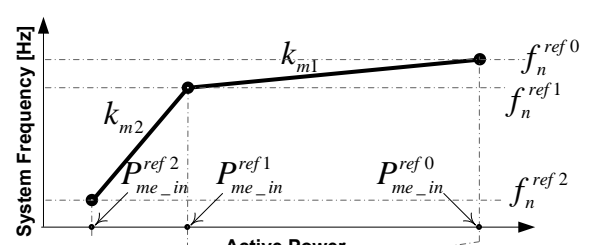

Active Power

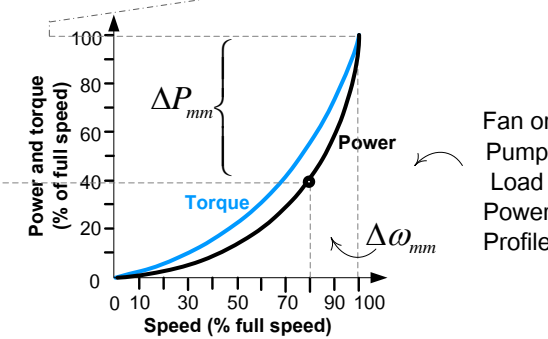

a) Changes in network frequency imposing a high power reduction on fan loads result in a small change in the fan speed.
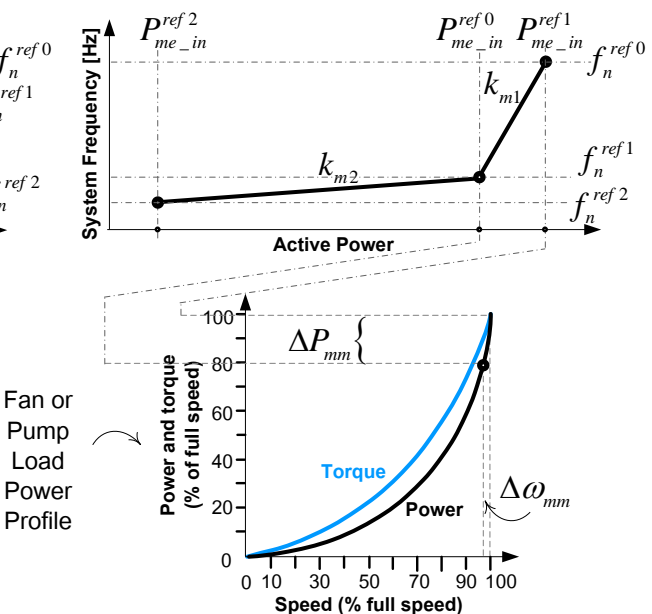

b) Changes in network frequency imposing a low power reduction on fan loads result in a even a smaller change in the fan speed.
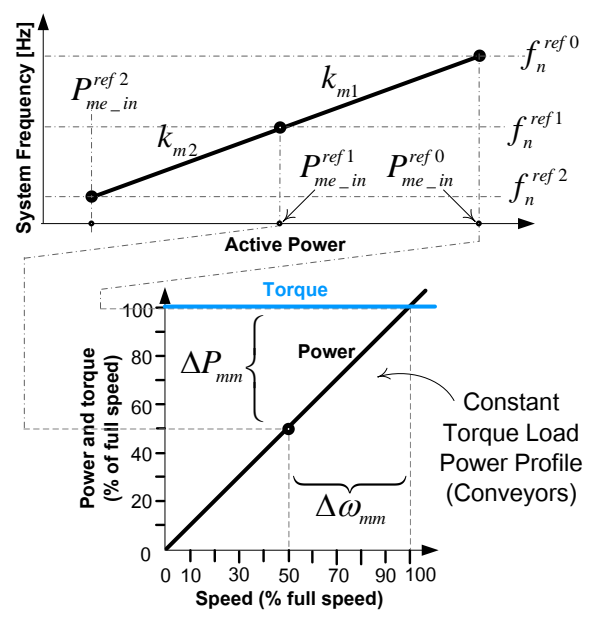

c) Changes in the network frequency imposing a proportional power reduction in constant torque loads result in a proportional reduction in the speed.

Fig. 4. Power-frequency droop lines with two droop factors and their impact on the speed of square torque loads (fans and pumps) and constant torque loads.

$$
P_{m e_{-} i n}^{*}=P_{m e_{-} i n}^{r e f} k_{m}
$$

Proportionality indices $p_{1}$ and $p_{2}$, and network frequency $f_{n}^{01}$ and $f_{n}^{12}$ values in (10) are defined by:

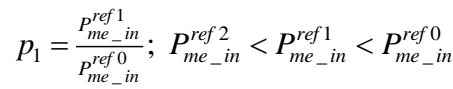

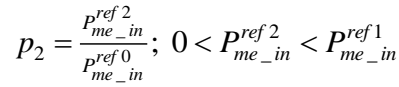

$$
\begin{aligned}
& 0 \leq p_{2} \leq p_{1} \leq 1 . \\
& f_{n}^{01}=f_{n} ; \quad f_{n}^{r e f 1} \leq f_{n}^{01} \leq f_{n}^{r e f 0} \\
& f_{n}^{12}=f_{n} ; \quad f_{n}^{r e f 2} \leq f_{n}^{12} \leq f_{n}^{r e f 1} \\
& f_{n}^{r e f 2} \leq f_{n}^{r e f 1} \leq f_{n}^{r e f 0}
\end{aligned}
$$

Equation (11) is a general expression from which the desired motor power can be obtained according to a change in the network frequency and a reference power $P_{m e}^{r e f}{ }_{i n}$. The droop factor $k_{m}$ relates the proportion in power reduction to changes in the network frequency.

By knowing $P_{m e}^{r e f}$ in $i n$ advance, when implementing (10), the value of $p_{1}$ can be set by specifying the minimum desired power value, $P_{m e-i n}^{r e f}$, for the region defined by the droop gain $k_{m 1}$. Better yet, since (10) has been per-unitized in terms of power, the value of $p_{1}$ can be arbitrarily set to have a value between 1 and $p_{2}$, as defined by (14), without even knowing the value of $P_{m e-i n}^{r e f}$ or $P_{m e}^{\text {ref } 1}$ in in advance. This is because the value of $P_{m e_{-} i n}^{r e f}$ is a function of $p_{1}$ and $P_{m e_{-} i n}^{r e f}$ as given by (12). By setting $p_{1}=0.4$, for example, one is indirectly defining $P_{m e_{-i n}}^{r e f 1}$ to be $40 \%$ of any given $P_{m e_{-} \text {in }}^{r e f}$. Similarly, $p_{2}$ can be arbitrarily set to have a value between $p_{1}$ and 0 . Setting $p_{2}=0.2$, for example, indirectly defines $P_{m e_{i} i n}^{\text {ref } 2}$ to be $20 \%$ of any given $P_{m e}^{\text {ref }} 0$.

Setting $f_{n}^{\text {refo }}$, defines at what frequency threshold the power-frequency support must be triggered such that the AC

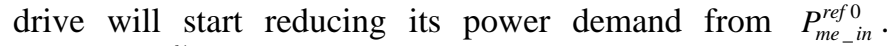
Setting $f_{n}^{r e f 1}$, defines at what frequency threshold the rate of change of power support with respect to the network frequency will transition from that defined by $k_{p m 1}$ to that defined by $k_{p m 2}$. Setting $f_{n}^{r e f 2}$, defines at what frequency threshold the AC drive must be triggered for load shedding, see Fig. 5.

Values of frequency thresholds $f_{n}^{\text {ref } 0}, f_{n}^{\text {ref } 0}, f_{n}^{\text {ref } 1}$ and $f_{n}^{r e f} 2$ are strongly dependant on the frequency of the network and on the frequency limits defined by the network operator. Setting these thresholds would be different for a $50 \mathrm{~Hz}$ network than for a $60 \mathrm{~Hz}$ network. Section V of this paper gives an example for the UK electric network.

When implementing (10) and (11), the proportionality indices $p_{1}$ and $p_{2}$ and frequency thresholds $f_{n}^{\text {ref } 0}, f_{n}^{\text {ref } 1}$ and $f_{n}^{r e f 2}$ remain constant while $f_{n}^{01}$ and $f_{n}^{12}$ vary as the network frequency varies as stated by (15) and (16) respectively. Thus, the only variables in (10) are $f_{n}^{01}$ and $f_{n}^{12}$. Furthermore, the last term in (10) is equal to zero until $f_{n}^{12}$ reaches a value equal to or less than $f_{n}^{\text {ref } 1}$. When $f_{n}^{12}$ reaches a value equal to or less than $f_{n}^{r e f 1}$, the previous term in (10) is held constant by holding $f_{n}^{01}$ equal to $f_{n}^{\text {ref } 1}$ while $f_{n}^{12}$ is left to vary between $f_{n}^{r e f 1}$ and $f_{n}^{r e f 2}$ as the network frequency varies.

A further advantage of implementing (10) is that the multidroop line characteristic can be modified online. The power variation with frequency drop can be adjusted as required by manipulating $p_{1}, p_{2}, f_{n}^{\text {ref } 0}, f_{n}^{\text {ref } 1}$ or $f_{n}^{\text {ref } 2}$ in (10). Examples of this are given in Figs. 4a-c. Droop factors $k_{p m 1}$ and $k_{p m 2}$ are indirectly defined when setting $p_{1}, p_{2}, f_{n}^{r e f 0}, f_{n}^{\text {ref } 1}$ and $f_{n}^{\text {ref } 2}$ in (10).

\section{General Control Structure for Network Power-Frequency Support by AC drives}

The effect of reducing the load power depends on the torque-speed characteristic of the driven load. An example is shown in Figs. 4a-b for a pump or fan, and the proposed technique is also valid for constant torque loads, as shown in Fig. 4c, since in both cases, the input power reduces as the speed reduces [19]. It is not valid for constant power loads, where reducing the input power would prevent the load from operating.

Assuming a fixed machine efficiency, the relationship 


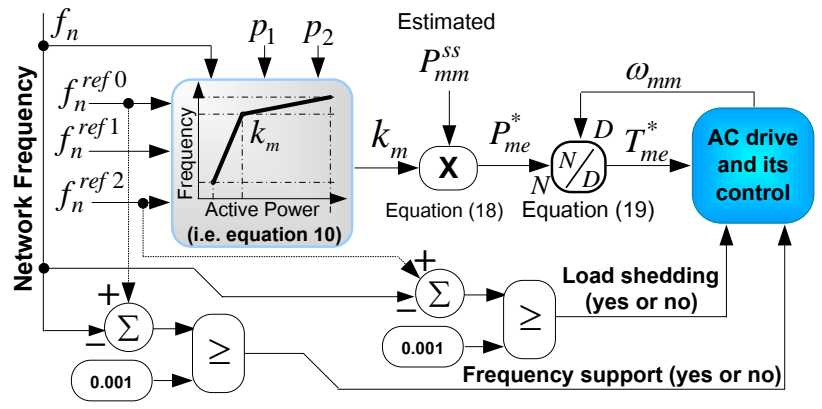

Fig. 5. General network power-frequency support by the participation of AC drives by using a multi droop line approach.

between the actual input power to the motor and the electric power required to drive the load (5) is linear, hence (11)can be rewritten as (18). Assuming steady state conditions, the adjustment factor also impacts the mechanical power consumed by the load, where $P_{m m}^{s s}$ is the steady state load power that would result if frequency support was not used. The use of the steady-state power in (18) also neglects the stored kinetic energy in the load, which will also contribute to the frequency support, as discussed in Section III.

$$
P_{m e}^{*}=P_{m e}^{r e f 0} k_{m}=P_{m e}^{s s} k_{m}=P_{m m}^{s s} k_{m}
$$

Hence, from (4) and (18), the reference torque $T_{m e}^{*}$ can be adjusted to control input power.

$$
P_{m e}^{*}=\omega_{m m} T_{m e}^{*}
$$

From (18), a reference power $P_{m e}^{*}$ for the motor can be generated from $P_{m m}^{s s}$ and $k_{m}$. Similarly, from (19), a torque reference $T_{m e}^{*}$ can be generated provided $P_{m e}^{*}$ as given by (18). Fig. 5 offers a general diagram for power-frequency support, where the measured network frequency is used to calculate the scale factor (10), and adjust the power (18) and hence torque references (19). Threshold logic is used to activate the frequency support mode and also to trigger load shedding at the minimum frequency.

\section{APPLICATION EXAMPLE 1 AND EXPERIMENTAL VALIDATION - FAN LOAD}

There is a cubic relationship between power $\left(P_{m m}\right)$ and speed $\left(\omega_{m m}\right)$ for a fan load (20), assuming the fan is rigidly coupled to the motor shaft [20]. However the cooling effect of the fan is determined by the flow rate, which varies linearly with speed. When controlling the air flow by controlling the fan speed, a small change in speed $\left(\Delta \omega_{m m}\right)$ will result in a large change in power $\left(\Delta P_{m m}\right)$, see Fig. 4 a, with only a small effect on the air flow [21]-[24]. This paper takes advantage of this to provide "virtual" energy storage: changing load power to provide network support, with minimal impact on the load.

$$
P_{m m}=\omega_{m m} T_{l}=K_{f a n} \omega_{m m}^{3}
$$

The power reference for the $\mathrm{AC}$ drive powering a fan is set as given by the power-frequency droop line shown in Fig. 6. It considers operational $(49.8 \mathrm{~Hz}, 50.2 \mathrm{~Hz})$ and statutory $(49.5 \mathrm{~Hz}, 50.5 \mathrm{~Hz})$ frequency limits imposed by the UK power network's operator, National Grid. In the UK there are three dynamic frequency response mechanisms defined as [8]:

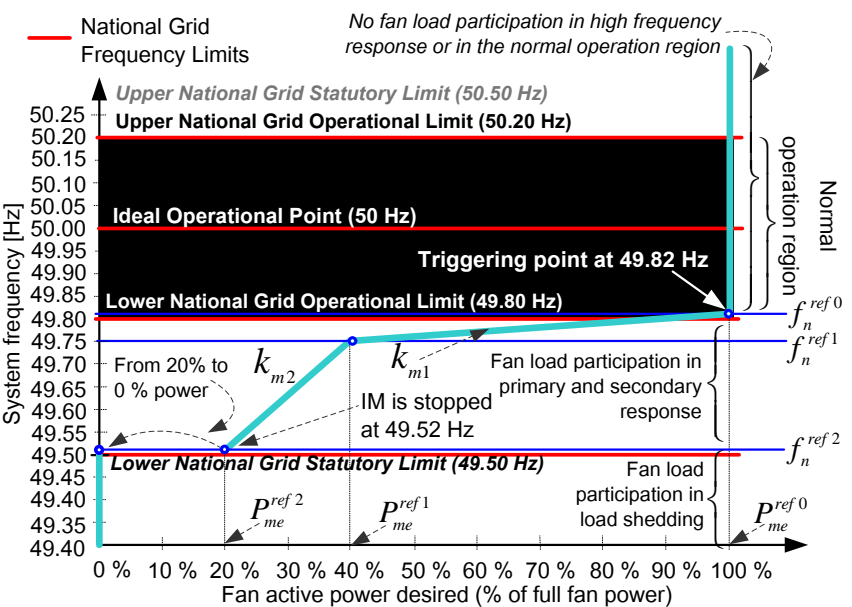

Fig. 6. Network power-frequency droop line applied to the fan load. Frequency thresholds are summarized in Table I.

TABLE I: NETWORK POWER-FREQUENCY DROOP PARAMETERS

\begin{tabular}{c|c|c|c|c}
\hline \multicolumn{3}{c|}{ Frequency Limits $(\mathrm{Hz})$} & \multicolumn{2}{c}{$\begin{array}{c}\text { Proportionality indices (per unitized } \\
\text { percentage of power limits needed for }(10))\end{array}$} \\
\hline$f_{n}^{\text {ref } 0}$ & $f_{n}^{\text {ref } 1}$ & $f_{n}^{\text {ref } 2}$ & $p_{1}$ & $p_{2}$ \\
\hline 49.82 & 49.75 & 49.52 & 0.4 & 0.2 \\
\hline
\end{tabular}

a) Primary frequency response: provision of active power (or a decrease in demand) within 10 seconds after an event.

b) Secondary frequency response: provision of active power (or decrease in demand) within 30 seconds after an event.

c) High frequency response: the reduction in active power generation within 10 seconds after an event.

The UK's network frequency is nominally $50 \mathrm{~Hz}$. The region delimited by the NG operational limits is considered the normal operating condition of the network. In the "high frequency response" region (above $50.20 \mathrm{~Hz}$ ), generation exceeds the demand. Increasing the power demand in this region would be a waste of energy, therefore, no load participation by the AC drive is considered above $50.20 \mathrm{~Hz}$. $49.8 \mathrm{~Hz}$ is at the limit of normal network operation. Thus, all frequencies above $49.82 \mathrm{~Hz}$ are rejected for load power reduction. The network will benefit from the AC drive starting to reduce its power from $49.82 \mathrm{~Hz}$ downwards. In the region defined by $k_{m 1}$, the reduction in the AC drive - fan power is from $100 \%$ to $40 \%$ in proportion to the network frequency. This effect can be added to the primary frequency response mechanism. If we add the effect of many AC drives powering fan loads in the system, the result is more likely to be large enough to keep the system frequency at acceptable levels as discussed in section VI. In the region defined by $k_{m 2}$, the rate of power reduction is less than in the first region. This is because most of the support wanted from the AC fan drive was delivered during the first seconds of the deviation of the network frequency from the operational limits. By the time the network frequency has reached $49.75 \mathrm{~Hz}$, other control schemes to compensate for the deviation in the system frequency should have been activated, such as the secondary frequency response mechanism. However, there is still more room (from the AC drive - fan) to provide power support to the network in case the deviation of the system frequency is 
beyond $49.75 \mathrm{~Hz}$. By the time the system frequency has achieved a value of $49.52 \mathrm{~Hz}$, the AC drive-fan has been stopped, since this might be an indication that something worse has happened in the network and there is no reason to keep the fan running at lower power. Therefore, $20 \%$ of the target active power consumed by the fan (in steady-state conditions) defines the latest operational point.

\section{A. AC Fan Drive Hardware Configuration}

The AC Drive and fan, used to prove the power-frequency concept, is shown in Fig. 7a. It consists of a SCHAFFNER NSG 1007-5 controllable variable three-phase voltagefrequency source rated at $300 \mathrm{~V}-16 \mathrm{~A}$ (phase rms) which can generate steps down and steps up in frequency with a resolution of $0.01 \mathrm{~Hz}$. The three-phase AC to $\mathrm{DC}$ conversion is achieved by a SEMIKRON SKD100/16 diode bridge rectifier rated at $110 \mathrm{~A}$ and $1.6 \mathrm{kV}$ (blocking voltage). The $\mathrm{DC}$ capacitors are rated at $450 \mathrm{~V} \mathrm{DC}, 2200 \mu \mathrm{F}( \pm 20 \%),-40 /+85^{\circ} \mathrm{C}$. Polypropylene snubber capacitors are implemented to suppress transient voltages. A Mitsubishi PM150CL1A120 IGBT Intelligent Power Module (IPM) is used to invert the voltage from DC to AC, rated at $120 \mathrm{~kW}, 150 \mathrm{~A}, 800 \mathrm{~V}$ DC. A $4.5 \mathrm{kHz}$ switching frequency was used with $2 \mu \mathrm{s}$ dead time and sine-triangle PWM (SPWM). The IM is rated at $4 \mathrm{~kW}$, $400 \mathrm{~V} \mathrm{rms}$ line to line, $2850 \mathrm{RPM}$, two poles. It is directly coupled to a fully enclosed centrifugal fan (commercially bought in packaged unit). Parameters of the IM and fan load are given in Table II, and further information on experimental characterisation can be found in [20].

\section{B. AC Drive Vector Control Implementation}

The main hardware control structure is shown in Fig. 7b-c. Line to line network voltages $v_{a b n}$ and $v_{b c n}$, IM stator currents $i_{a s I M}$ and $i_{b s I M}$ and rotor speed are measured. A NI PXI$7851 \mathrm{R}$ card with integrated analogue and digital input/outputs with FPGA technology was employed for the control structure shown in Fig. 7b.

"Indirect rotor flux oriented control (IRFOC)" was used to provide high bandwidth control of torque, which in turn provides high bandwidth control of active power [25]. The control of the mechanical speed is achieved by a proportional integral controller (PI) acting on the speed error $\left(\omega_{m m}^{*}-\omega_{m m}\right)$ which in turn generates the corresponding torque command. $\omega_{m m}^{*}$ would be generated by a slowly varying target speed reference $\omega_{m m}^{t a r}$ (coming from a thermostat for example) and a slew rate limiter to ramp the IM rotor speed reference up/down. The torque command sent to the IRFOC is cascaded with a proportional integral current controller (not shown in Fig. $7 \mathrm{~b}$ for simplicity). Damping factors and bandwidth used for the controllers are as given in Table III.

A slew rate limiter is configured to allow the reference for

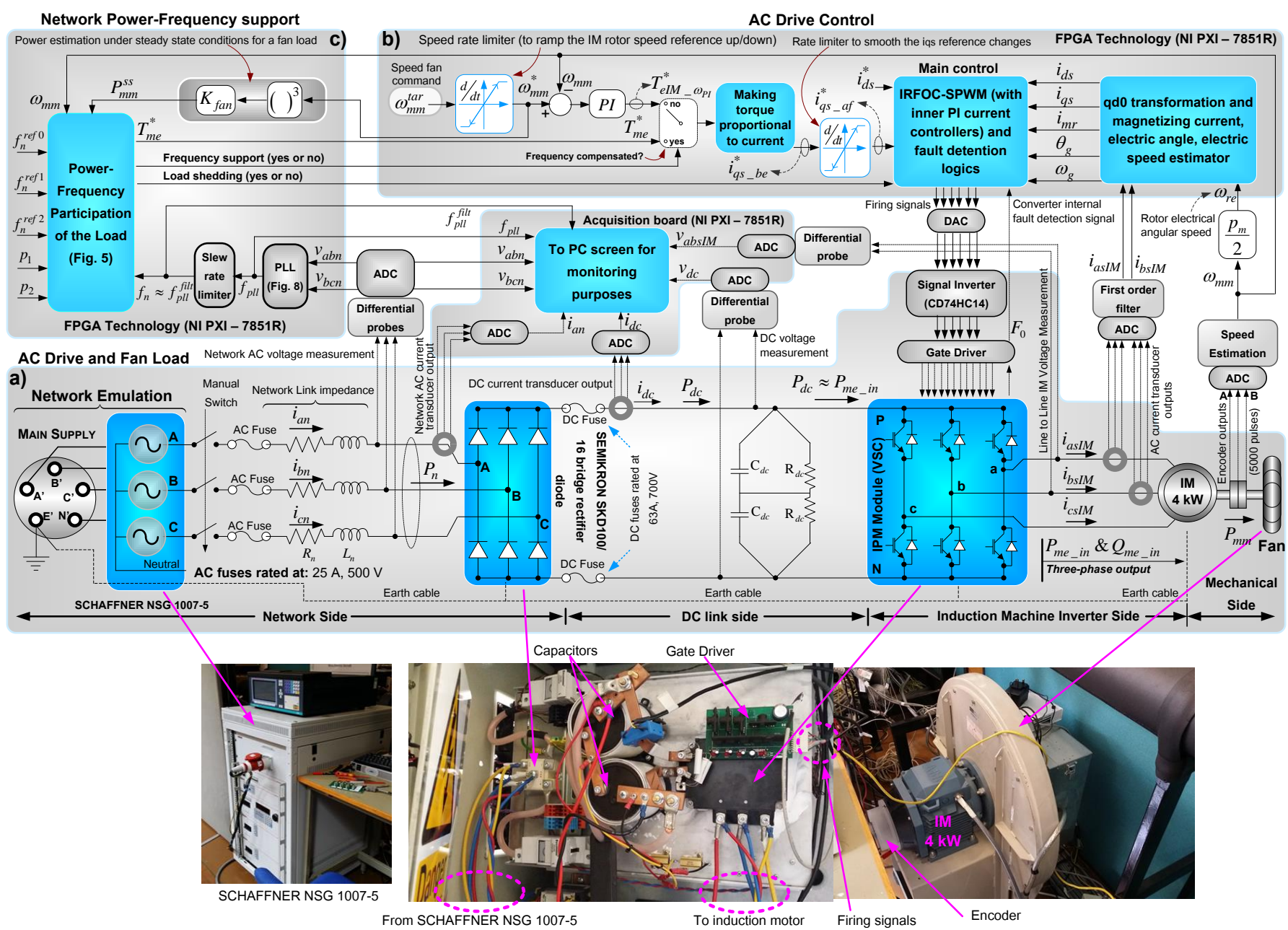

Fig. 7. Test hardware: (a) AC drive hardware configuration, (b) AC drive vector control and (c) network power frequency droop control implementation. 
the current PI controller ( $i_{q s_{-} a f}^{*}$ ) to change by $50 \mu \mathrm{A}$ per $20 \mu \mathrm{s}$ (i.e. with a slope of $2.5 \mathrm{~A} / \mathrm{s}$ ) under transient conditions; as an example if the desired stator current $q$ component $\left(i_{q s_{-} b e}^{*}\right)$ is switched from $2.5 \mathrm{~A}$ to $0 \mathrm{~A}$, the desired stator current $q$ component $i_{q s_{-} a f}^{*}$ for the PI controller will be ramped from $2.5 \mathrm{~A}$ to $0 \mathrm{~A}$ and it will take $1 \mathrm{~s}$ for $i_{q s_{-} a f}^{*}$ to be equal to $i_{q s_{-} b e}^{*}$. The output from the slew rate limiter $\left(i_{q s_{-} a f}^{*}\right)$ is taken as the current reference for the PI controller.

\section{Power-Frequency Droop Control Implementation}

The network power-frequency support is achieved by the coordination of the power-frequency algorithm shown in Fig. 5 to modify the torque reference for the IRFOC of the IM as shown in Figs. 7b-c. The frequency limits and proportionality indices are as given in Table I. In this implementation, the network active power $\left(P_{n}\right)$ is indirectly controlled by controlling $P_{m e}$. However, in practice, motor and converter efficiency will vary with load, so the relationship will not be exactly linear. The steady-state load power value needed for $P_{m m}^{s s}$ is calculated by substituting $\omega_{m m}$ for $\omega_{m m}^{*}$ in (20).

In Fig. 7c, the network frequency is estimated by implementing a Phase-Locked Loop (PLL) algorithm as shown in Fig. 8 [26-27]. Line to line voltages $v_{a b n}$ and $v_{b c n}$ are transformed to the synchronous $q d$ reference frame (where the $q$ axis is leading the $d$ axis by 90 degrees). The line to line network voltage magnitude $\left(v_{l l}\right)$ is forced to align with the $q$ axis by a proportional-integral controller $\left(P I_{p l l}\right)$ acting on the component error $v_{d_{l l}}$. The $P I_{p l l}$ controller produces an angular speed command $\omega_{P I}$ which is compensated by the nominal network angular speed $\omega_{\text {pllo }}$ (i.e. $50 \mathrm{~Hz}$ or $60 \mathrm{~Hz}$ ) resulting in the estimation of the instantaneous network angular speed $\omega_{p l l}$ (in rad/s) and frequency $f_{\text {pll }}$ (in $\mathrm{Hz}$ ). The loop is closed by the generation of the transformation angle $\theta_{v_{a b n}}$ by the angle oscillator. $P I_{p l l}$ parameters are as given in Table IV.

The controllable voltage source produces pure sinusoidal voltages. However, the real voltages at the distribution side of a network are usually non ideal due to the effect of loadswitching by other users, commutation by nearby power electronic equipment and the additional transient effects of lightning strikes and distribution faults [28]. Hence, to get a closer representation of the worst-case network voltage shape in the real world, the voltages used to estimate the network frequency, for the results shown in the next section, are the voltages at the input of the passive rectifier (as shown in Fig. 7); these voltages are a function of the network impedance and the non-linear current drawn by the passive rectifier, making the $\mathrm{AC}$ voltages distorted, see Fig. 9c.

Distorted voltages introduce noise in the frequency estimated by the PLL. Therefore, $f_{\text {pll }}$ is smoothed through the slew-rate limiter shown in Fig. 7c. Filtering of the network voltages would be another possibility. However, the implementation of a slew rate limiter needs fewer FPGA resources than a low pass filter [20]. The rate limiter is configured to allow the measured frequency $\left(f_{p l l}\right)$ to change by $10 \mu \mathrm{Hz}$ per $20 \mu \mathrm{s}$ under transient conditions (i.e. with a slope of $0.5 \mathrm{~Hz} / \mathrm{s})$. This ensures that if the network frequency

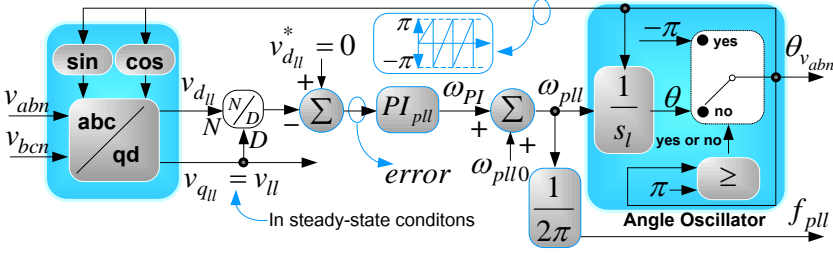

Fig. 8. PLL Implementation.

TABLE II: AC DRIVE PARAMETERS [20]

\begin{tabular}{|c|c|c|c|c|}
\hline \multicolumn{2}{|c|}{ Network Impedance } & \multicolumn{3}{|c|}{ DC Link Impedance } \\
\hline$R_{n}=0.2 \Omega$ & $L_{n}=0.001585 H$ & $R_{d c}=3300$ & $25 W)$ & $\mathrm{C}_{d c}=2200 \mu \mathrm{F}$ \\
\hline \multicolumn{5}{|c|}{ Induction Machine Parameters } \\
\hline \multicolumn{2}{|c|}{$R_{s}($ stator resistance $)=1.61 \Omega$} & \multicolumn{3}{|c|}{$L_{r}{ }^{\prime}($ rotor leakage-inductance $)=0.007 \mathrm{H}$} \\
\hline \multicolumn{2}{|c|}{$R_{r}{ }^{\prime}($ rotor resistance $)=1.00 \Omega$} & \multicolumn{3}{|c|}{$L_{s}($ stator leakage-inductance $)=0.007 \mathrm{H}$} \\
\hline \multicolumn{3}{|c|}{$L_{m}($ magnetizing resistance $)=0.293 \mathrm{H}$} & \multirow{2}{*}{\multicolumn{2}{|c|}{$\begin{array}{l}\text { The superscript (') } \\
\text { means quantity referred } \\
\text { to the stator }\end{array}$}} \\
\hline \multicolumn{3}{|c|}{$J_{\text {motor }}($ rotor moment of inertia $)=0.010 \mathrm{kgm}^{2}$} & & \\
\hline \multicolumn{5}{|c|}{ Fan Parameters } \\
\hline \multicolumn{2}{|c|}{ Nominal power $=4 \mathrm{~kW}$} & \multicolumn{3}{|c|}{$J_{\text {fan }}($ moment of inertia $)=0.7636 \mathrm{kgm}^{2}$} \\
\hline \multicolumn{2}{|c|}{ Nominal speed $=2850 \mathrm{rpm}$} & \multicolumn{3}{|c|}{$K_{f a n}=0.00012798 \mathrm{Nms}^{2} \mathrm{rad}^{-2}$} \\
\hline
\end{tabular}

TABLE III: PI CURRENT AND SPEED CONTROL PARAMETERS [20]

\begin{tabular}{l|c|l|c}
\hline \multicolumn{2}{c|}{ Current Control Loops } & \multicolumn{2}{c}{ Speed Control Loop } \\
\hline$\zeta_{i}($ damping factor $)$ & 1 & $\zeta_{s}($ damping factor $)$ & 0.8 \\
\hline$\omega_{n i}($ bandwidth $)$ & $1571 \mathrm{rad} / \mathrm{s}$ & $\omega_{n s}$ (bandwidth) & $0.247 \mathrm{rad} / \mathrm{s}$ \\
\hline
\end{tabular}

TABLE IV: PI PARAMETERS FOR THE PLL

\begin{tabular}{|c|c|c|}
\hline$P I_{p l l}=s_{l}^{-1} k_{i p l l}+k_{p p l l}$ & $k_{p p l l}=2 \zeta_{p l l} \omega_{n p l l}$ & $k_{i p l l}=\omega_{n p l l}^{2}$ \\
\hline$\zeta_{p l l}($ damping factor $)=1$ & $\omega_{\text {npll }}$ (ban & th) $=2 \pi \mathrm{rad} / \mathrm{s}$ \\
\hline
\end{tabular}

suddenly drops from $50 \mathrm{~Hz}$ to $49.5 \mathrm{~Hz}$, the slew rate limiter output ( $\left.f_{\text {pll }}^{\text {filt }}\right)$ will achieve this value $(49.5 \mathrm{~Hz})$, ideally, in $1 \mathrm{~s}$. This is fast enough for the control to trigger the IM for low network frequency load shedding.

\section{Experimental Results}

Fig. 9 shows the start-up, acceleration to full speed and normal operation of the fan drive. Fig. 9a-b shows the speed and inner current control loops experimental results acquired by applying the IRFOC to the AC drive. The stator $d$ current component reference $\left(i_{d s}^{*}\right)$ was set to 3.6 Amps at 5 s (Fig. 9b) and it was kept at this value during the full operation of the AC drive. As the magnetizing current is kept constant $\left(i_{m r} \approx i_{d s}\right)$, the torque $\left(T_{m e}\right)$ is proportional to the stator $i_{q s}$ current component [25]. At 10s, the rotor speed reference was ramped up from $0 \mathrm{rad} / \mathrm{s}$ to $180 \mathrm{rad} / \mathrm{s}$ as shown in Fig. 9a. The speed PI controller provides the desired torque $\left(T_{e I M_{-} \omega_{P I}}^{*}\right)$. As the rotor speed reference increases, the IM accelerates.

The IM currents are sampled, filtered and transformed to $q d$ values at a rate of $330 \mathrm{kHz}$. A first order low pass filter was programed in the FPGA with a bandwidth of half of the switching frequency in order to reject the switching effect due to the SPWM modulation and hence to extract the main component of the IM current. The resultant filtered current for the phase "a" is shown in Fig. 9g. Since a high bandwidth was employed for the filter, this did not have a significant impact on the closed loop control performance. 

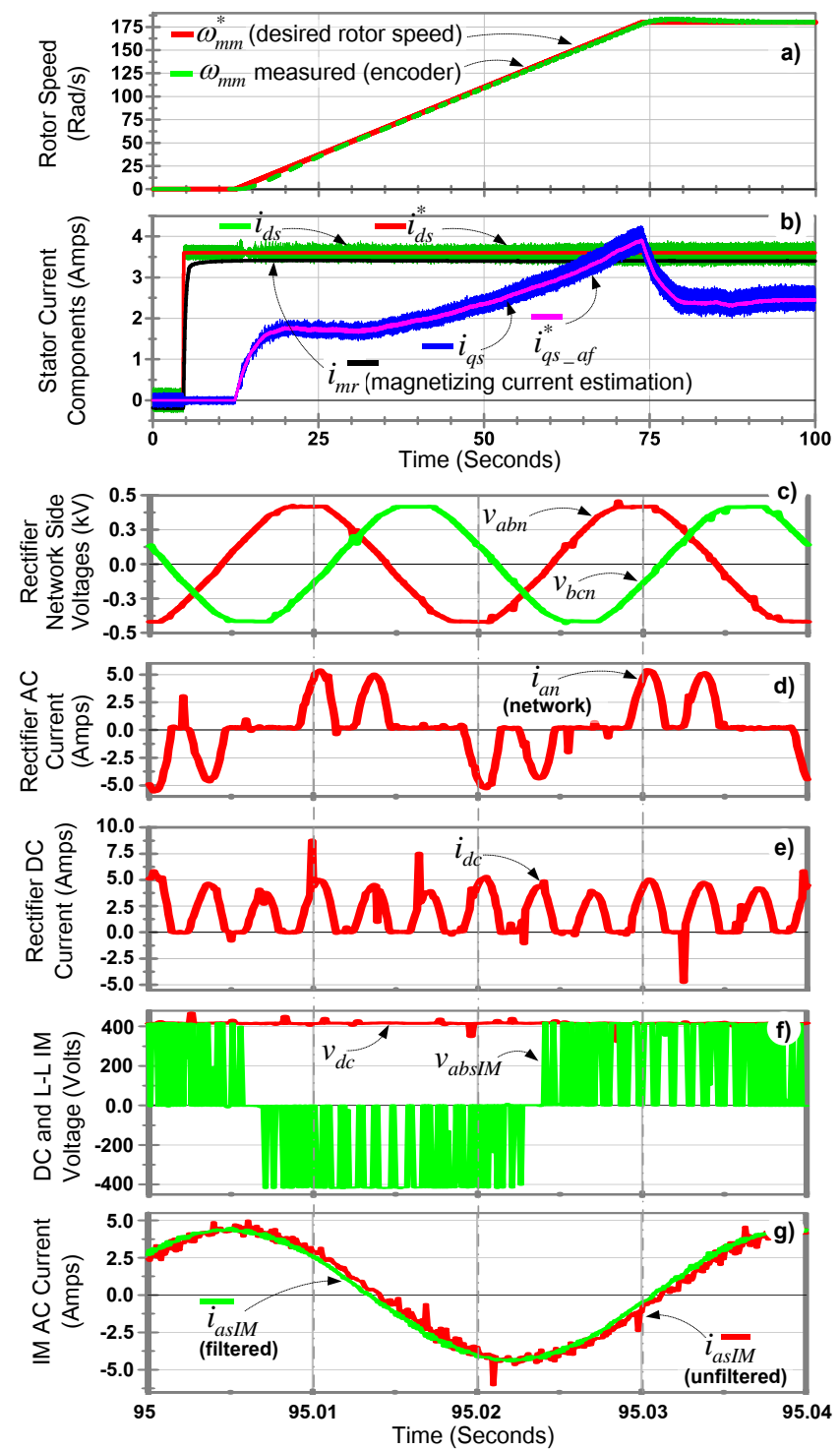

Fig. 9. Experimental results: (a) speed control, (b) current control loops response and steady state behavior (c-g) of the system shown in Fig. 7.

Fig. 9c-g shows the steady state behaviour of the AC drive. Converter switching can be observed as voltage spikes in the DC link voltage $\left(v_{d c}\right)$. This effect also propagates to the network side of the AC drive. Notches in the line to line voltages of the network side $v_{a b n}$ and $v_{b c n}$ can be observed. Although the effect of the stray inductance has been minimized with the addition of snubber capacitors, its effect cannot be suppressed completely. Currents at the network side $\left(i_{a n}\right)$ and DC side $\left(i_{d c}\right)$ follow a characteristic shape for this type of topology, despite the presence of voltage spikes in the system. A full simulation and experimental benchmarking of this AC drive topology (Fig. 7a) can be found in [20].

Fig 10 shows the smart load response to step changes in system frequency; at $150.5 \mathrm{~s}$, the network frequency dropped from $50 \mathrm{~Hz}$ to a value of $49.60 \mathrm{~Hz}$, and at $172.5 \mathrm{~s}$ the frequency was returned to $50 \mathrm{~Hz}$. Fig. 10a-b shows the network frequency estimation by the PLL (Fig. 8). Results show that, even with the use of a very small bandwidth, noise distortion of the voltage propagates to the PLL error, which in turn impacts the estimation of the system frequency $\left(f_{p l l}\right)$ producing false estimations which varies from $47.5 \mathrm{~Hz}$ to 52.5 Hz. However, the implementation of a slew rate limiter helps to suppress false estimations of the system frequency and kept a better approximation $\left(f_{\text {pll }}^{\text {fil }}\right)$ at the cost of a slower response. Nevertheless, this response is still fast enough for its consideration in the frequency primary response mechanism.

Fig. 10c shows the contribution of the AC drive active power to changes of the network frequency. At 151s, when the frequency at the output of the slew rate limiter $\left(f_{\text {pll }}^{\text {filt }}\right)$, achieved $49.82 \mathrm{~Hz}$, the control structure (Fig. 7c) generated a desired torque $\left(T_{m e}^{*}\right)$ corresponding to this frequency and it switched the control structure in Fig. 7b (by the use of the frequency support command) from speed closed loop control $\left(\omega_{m m}^{*}\right)$ to open loop torque control $\left(T_{m e}^{*}\right)$. As the speed control loop is opened, its PI controller output $\left(T_{e l M_{-} \omega_{P I}}^{*}\right)$ saturates as shown in Fig. 10d. During low network frequency conditions, the open loop torque control reference $\left(T_{m e}^{*}\right)$ is produced from the actual rotor speed $\left(\omega_{m m}\right)$ and the desired active power $\left(P_{m e}^{*}\right)$ for the AC drive under low network frequency conditions $\left(f_{n} \leq 49.82 \mathrm{~Hz}\right)$ as shown in Fig. 5. Changing from $T_{e I M_{-} \omega_{P I}}$ to $T_{m e}^{*}$, directly impacts the desired torque current component $\left(i_{q s_{-} b e}^{*}\right)$, Fig. 10e. However, these changes are smoothed by the slew rate current limiter shown in Fig. $7 \mathrm{~b}$.

As the torque reference $\left(T_{m e}^{*}\right)$ is decreased, the IM power is decreased $\left(P_{m e}\right)$ and the network power $\left(P_{n}\right)$ is decreased as well, as can be seen in Fig. 10c. A full response is achieved in about 1.5s. This is fast enough for the IM fan load to participate in the "primary response" mechanism which requires a response within $10 \mathrm{~s}$ and to sustain the drop in power for a further 20s. It can be observed in Fig. 10c that the IM active power remains at the desired power proportional to the system frequency, even under variations of the IM speed $\left(\omega_{m m}\right.$, Fig. 101) and torque reference $\left(T_{m e}^{*}\right)$. Torque and speed change to adjust themselves to the desired power. Furthermore, there is not a rapid reduction in the rotor speed due to the spare energy stored in the system inertia being released to balance the power being drawn by the fan load.

The frequency of the network was kept at $49.60 \mathrm{~Hz}$ for $20 \mathrm{~s}$ to analyse the performance of the system. The fan speed is gradually reduced from $180 \mathrm{rad} / \mathrm{s}(100 \%)$ to $130 \mathrm{rad} / \mathrm{s}(72 \%)$. The network active power drawn by the AC drive went from 900 Watts (100\%) to 300 Watts (33\%) instantaneously.

The worst case scenario for system recovery would be if the frequency suddenly increases from a very low value to the normal operation condition $(50 \mathrm{~Hz})$. This is because the IM fan load could be suddenly switched from the powerfrequency control to the closed speed control and start to draw a very high power in a short period of time. Hence, at $172.5 \mathrm{~s}$ the network is returned to its nominal frequency, $50 \mathrm{~Hz}$. However, as can be seen in Fig. $10 \mathrm{~g}-\mathrm{j}$, the frequency slew rate limiter and the current slew rate limiter help to avoid a very fast transient from low network frequency conditions to normal network frequency conditions. However, there is still a very high power recovery period (although the system is in a safe condition). This was done intentionally to show that such a situation may happen and that some precautions must 

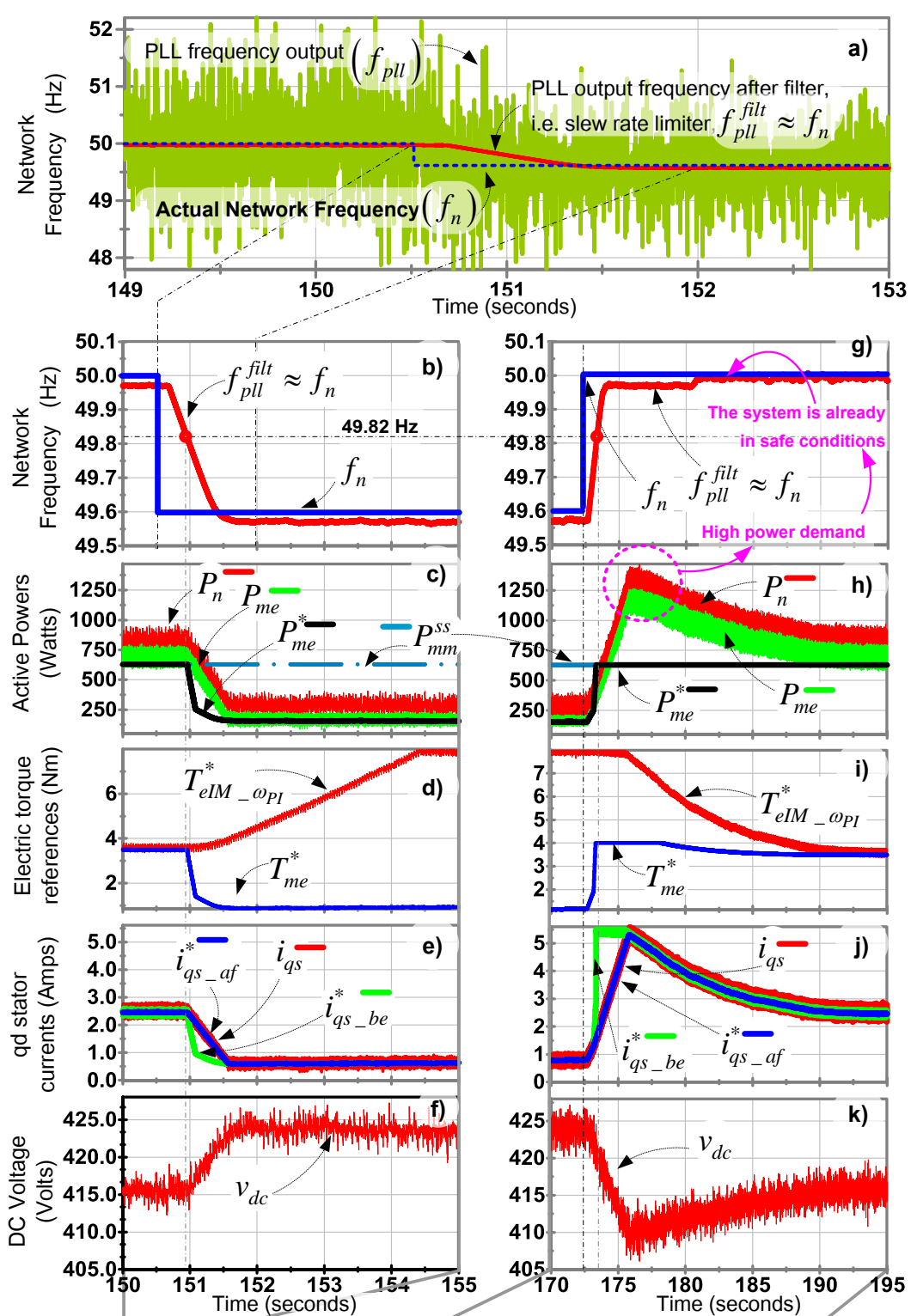

e)

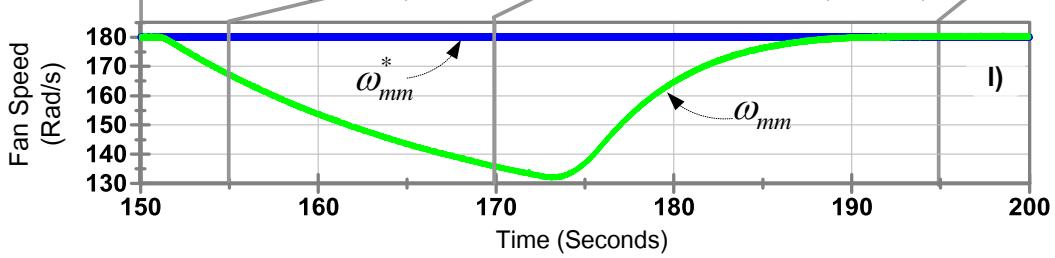

Fig. 10. Network power-frequency support experimental results of Fig. 7.

be taken. This phenomenon can be avoided by increasing the time the slew rate limiter takes to ramp up the current reference.

The system was also tested for load-shedding. At 220.6s, the network frequency was dropped to $49.4 \mathrm{~Hz}$, Fig. 11a. The frequency output of the slew rate limiter reached $49.52 \mathrm{~Hz}$ in about $1.5 \mathrm{~s}$. At this point the switches of the VSC were opened to stop the IM for this very low network frequency. Currents and powers (Fig. 11b) dropped to zero. The DC voltage $\left(v_{d c}\right)$ is returned to its nominal value under no load conditions. By 243s the network frequency has returned to its nominal frequency, but the load remains disconnected. The restoration of the load must be made manually in this case as a safety precaution; conditions for automatically restarting the load are beyond the scope of this paper.

\section{E. Stability of the DC Voltage}

The DC link dynamics are governed by the DC capacitance and by the nonlinear relationship between DC voltage, DC current and motor power demand. The small signal analysis governing the dynamics of the DC link reveals the existence of a negative impedance that could lead to instability of the AC drive [29]. If this is the case, the final torque command to the field oriented control can be further adjusted as recommended in [29] to achieved stabilization of the DC link. 


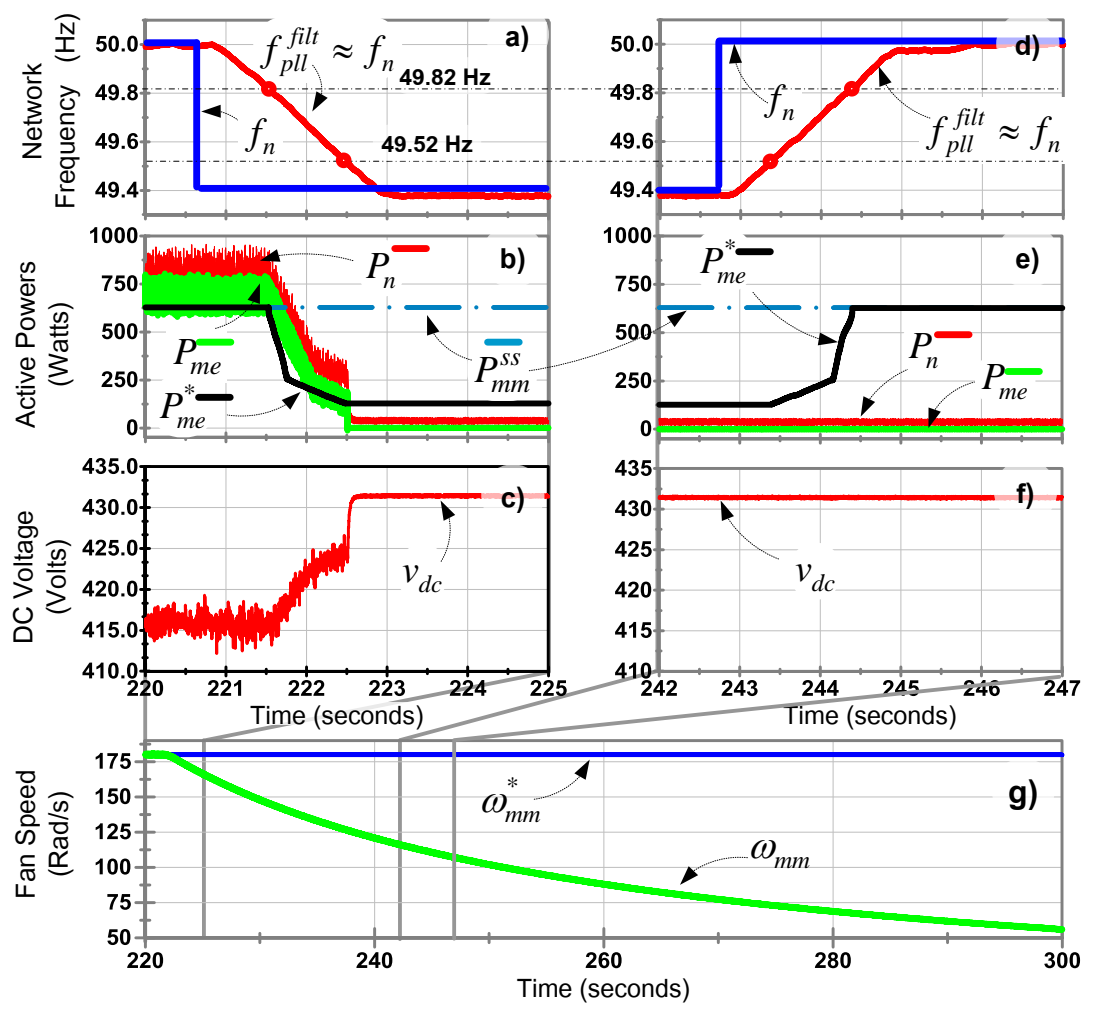

Fig. 11. Load-Shedding experimental results of Fig. 7.

\section{Wide Penetration of SMart Motor Drive LoAds IN LARGE POWER SYSTEMS AND INTERACTION WITH TRADITIONAL GENERATOR FREQUENCY CONTROL}

In EPNs most of the electricity is produced by large central generators, generally by synchronous generators driven by prime movers: usually turbines powered by steam, gas or water (hydro turbines). The turbine is equipped with a governor which in effect controls either its speed or output power according to its power-frequency characteristic [12]. For stable operation of the turbine, droop control is used for this purpose, as discussed in Section IV-A of this paper. The combination of many generation units helps to ensure that any power fluctuation produces small changes in the network frequency as shown in Fig. 3a.

Similarly, by combining the participation of many AC drives for network power-frequency support, a large amount of power reduction can be achieved if the network frequency were to drop as shown in Fig. 3b.

The interaction between the droop power-frequency characteristic of the synchronous generators and that of the load (AC drives) can be explained by analysing Fig. 12. In Fig. 12, if for some reason, the total load power were to increase from that required at point $\mathrm{A}$ to that required at point $\mathrm{B}$, the network frequency would drop from $f_{n 0}$ to $f_{n 1}$ so as to cope with the new power demand. However, when the effect of the AC drives, equipped with a droop control, is considered, the resultant effect is slightly different. If the network frequency reduces, the power drawn by the AC drives reduces as well from that required at point $\mathrm{C}$ to that required at point $\mathrm{D}$. This reduction in power allows the synchronous generators to accelerate and the system to achieve a different
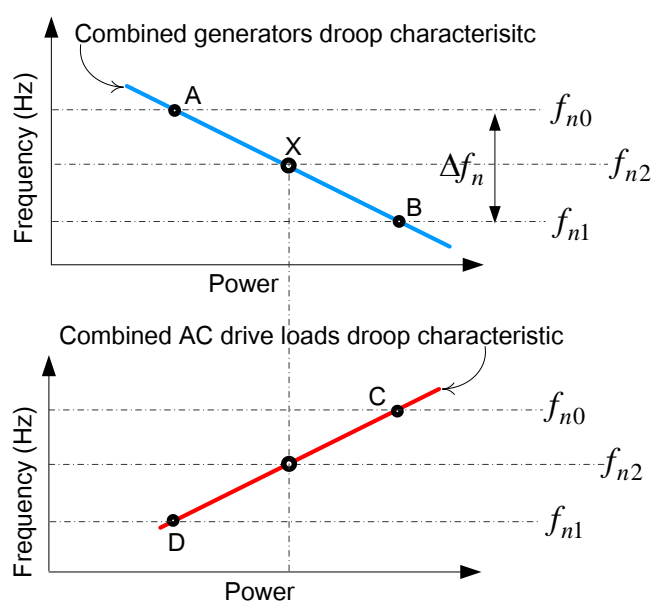

Fig. 12. Equilibrium between the combined generators droop characteristic and the combined $\mathrm{AC}$ drive loads droop characteristic.

operating point $(\mathrm{X})$ with a higher network frequency, $f_{n 2}$, compared to that when no participation of the AC drives is considered $\left(f_{n 1}\right)$.

\section{CONCLUSIONS}

Using AC drives as Smart-Loads is possible. Network power-frequency support is possible by fan loads powered by AC drives without overly disturbing the fan. When the electromechanical torque of the IM is controlled in open loop, the speed of the IM does not change quickly (but the electric power of the IM does). This is mainly due to cubic powerspeed relationship and to the spare energy stored in the system inertia, which allows the fan load to reduce its speed slowly. 
Such a disturbance would not have a huge impact on a fan used for heating, ventilation and air conditioning. However, such a reduction in power can help the recovery of the network under low frequency conditions or to avoid a worst case scenario. The functionality proposed in this paper is a relatively simple add-on that could be readily incorporated into standard commercial products. It is equally applicable to other machine types (e.g. PM, SR) and control methods (e.g. DTC, sensorless) since the frequency support algorithm only changes the reference torque command of the drive.

\section{REFERENCES}

[1] K. Li, J. Liu, Z. Wang and B. Wei. "Strategies and Operating Point Optimization of STATCOM Control for Voltage Unbalance Mitigation in Three-Phase Three-Wire Systems," Power Delivery, IEEE Transactions on, Vol. 22, No. 1, pp. 413-422, Jan. 2007.

[2] A. Arsoy, Y. Liu., S. Chen., Z. Yang; M.L. Crow and P.F. Ribeiro. "Dynamic performance of a static synchronous compensator with energy storage," PES Winter Meeting. IEEE, Vol. 2, No.w/o, pp. 605-610, 2001.

[3] J. Lee, G. Jang, E. Muljadi, F. Blaabjerg, Z. Chen and Y. Cheol Kang, "Stable Short-Term Frequency Support Using Adaptive Gains for a DFIG-Based Wind Power Plant," in IEEE Transactions on Energy Conversion, vol. 31, no. 3, pp. 1068-1079, Sept. 2016.

[4] Y. Cao et al., "A Virtual Synchronous Generator Control Strategy for VSC-MTDC System," in IEEE Transactions on Energy Conversion, vol. PP, no. 99, pp. 1-1, Nov. 2017.

[5] Paula S. Walmet. "Evaluation of Lead/Carbon Devices for Utility Applications: A Study for the DOE Energy Storage Program". SANDIA REPORT SAND2009-5537, Unlimited Release, Printed June 2009.

[6] W. W. Weaver and P. T. Krein, "Game-Theoretic Control of Small-Scale Power Systems," in IEEE Transactions on Power Delivery, vol. 24, no. 3, pp. 1560-1567, July 2009.

[7] Z. Akhtar, B. Chaudhuri and S. Y. R. Hui, "Primary Frequency Control Contribution From Smart Loads Using Reactive Compensation," IEEE Transactions on Smart Grid, vol. 6, no. 5, pp. 2356-2365, Sept. 2015.

[8] National Grid Electricity Transmission plc. "The Grid Code”. Issue 5, Revision 6, UK, 13 December 2013.

[9] Z. Xu, J. Ostergaard and M. Togeby, "Demand as Frequency Controlled Reserve," in IEEE Transactions on Power Systems, vol. 26, no. 3, pp. 1062-1071, Aug. 2011.

[10] A. Mondal, M. S. Illindala, A. S. Khalsa, D. A. Klapp and J. H. Eto, "Design and Operation of Smart Loads to Prevent Stalling in a Microgrid," in IEEE Transactions on Industry Applications, vol. 52, no. 2, pp. 1184-1192, March-April 2016.

[11] Labib, M. Billah, M. Rafiqul and G. M. Sultan. "Design and construction of smart load management system: An effective approach to manage consumer loads during power shortage," ICEEICT, pp. 1-4, Dhaka, 2015.

[12] J. Machowski, J. W. Bialek and J. R. Bumby. "Power System Dynamics: Stability and Control". Second Edition, John Wiley \& Sons Ltd., 2008.

[13] R. Garcia-Valle, L. C. P. da Silva, Z. Xu and J. Ostergaard. "Smart Demand for Improving Short-Term Voltage Control on Distribution Networks". Journals of the IET - Generation, Transmission and Distribution, Vol. 3, No. 8, pp. 724-732, August 2009.

[14] K. Tomiyama, J. P. Daniel and S. Ihara, "Modeling air conditioner load for power system studies," in IEEE Transactions on Power Systems, vol. 13, no. 2, pp. 414-421, May 1998.

[15] National Grid. "Power Responsive". Accessed on 16/12/2017: http://www.powerresponsive.com/

[16] F. Andrén, R. Bründlinger and T. Strasser, "IEC 61850/61499 Control of Distributed Energy Resources: Concept, Guidelines, and Implementation," in IEEE Transactions on Energy Conversion, vol. 29, no. 4, pp. 1008-1017, Dec. 2014.

[17] B. M. Weedy, B. J. Cory, N. Jenkins, J. B. Ekanayake and G. Strbac. "Electric Power Systems". Fifth Edition, WILEY, 2012.

[18] Rockwell Automation. "When to use a Soft Starter or an AC Variable Frequency Drive". A White Paper. 2014.

[19] A. T. de Almeida, F. J. T. E. Ferreira and D. Both, "Technical and economical considerations in the application of variable-speed drives with electric motor systems," in IEEE Transactions on Industry Applications, vol. 41, no. 1, pp. 188-199, Jan.-Feb. 2005.

[20] J. Carmona-Sanchez. "A Smart Adaptive Load for Power-Frequency Support Applications". PhD Thesis, The University of Manchester, UK, 2015.

[21] J. R. Eliason and B. S. Fisher, "Large Adjustable Speed Fan Drives Including Static Converter Developments for Cement Plants," in IEEE Transactions on Industry Applications, vol. IA-13, no. 6, pp. 557-562, Nov. 1977.

[22] W. L. Stebbins. "Are you certain you understand the economics for applying ASD systems to centrifugal loads?" Proceedings of 1994 IEEE/IAS Annual Textile, Fiber and Film Industry Technical Conference, Greenville, SC, 1994, pp. 1-8.

[23] R. Carlson. "The correct method of calculating energy savings to justify adjustable-frequency drives on pumps." in IEEE Transactions on Industry Applications, vol. 36, no. 6, pp. 1725-1733, Nov/Dec 2000.

[24] Arnab Chatterjee, Lijun Zhang, Xiaohua Xia. "Optimization of mine ventilation fan speeds according to ventilation on demand and time of use tariff". Elsevier, Applied Energy, Volume 146, Pages 65-73, 2015.

[25] D. W. Novotny and T. A. Lipo, "Vector Control and Dynamics of AC Drives", Oxford Science Publications, 1998.

[26] Chung, S.K., "Phase-locked loop for grid-connected three-phase power conversion systems," in Electric Power Applications, IEE Proceedings - , vol.147, no.3, pp.213-219, May 2000.

[27] E. Adzic, M. Adzic, J. Tomic, V. Katic. "Improved phase-locked loop for distributed power generation systems," IEEE 9th International Symposium on Intelligent Systems and Informatics, vol., no., pp.323328, Sept. 2011.

[28] ABB. Voltage ratings of high power Semiconductors. Application note 5SYA 2051. August 20, 2013.

[29] S. D. Sudhoff, K. A. Corzine, S. F. Glover, H. J. Hegner and H. N. Robey, "DC link stabilized field oriented control of electric propulsion systems," in IEEE Transactions on Energy Conversion, vol. 13, no. 1 , pp. 27-33, Mar 1998.

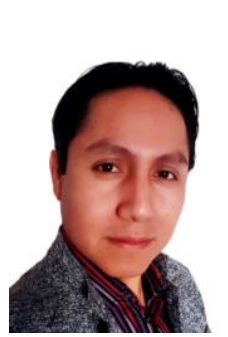

\section{BIOGRAPHIES}

Jesús Carmona-Sánchez received the B.E. degree in Electromechanical Engineering from Instituto Tecnológico de Acapulco (ITA), México in 2007, the M.Sc. degree in Electrical Engineering from Instituto Politécnico Nacional (IPN), Mexico in 2010 and his $\mathrm{PhD}$ from The University of Manchester, UK in 2016, where he is currently a Research Associate. His main interests lie on modelling, control and stability assessment of power electronic converters and smart multi-terminal HVDC networks.

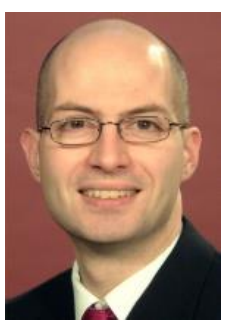

Mike Barnes (M'96) received the B.Eng. degree in engineering and the Ph.D. degree from the University of Warwick, Warwick, U.K., in 1993 and 1998 , respectively.

$\mathrm{He}$ is currently a Professor with the University of Manchester (formerly University of Manchester Institute of Science and Technology), Manchester, U.K. His principal research interests are in power electronics applied to machine drives and power systems.

Prof. Barnes is a member of the Institution of Electrical Engineers, U.K.

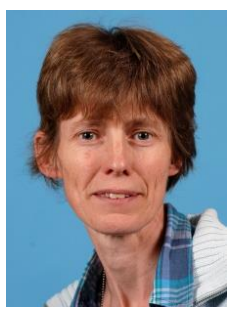

Judith M. Apsley (M’05) received her BA degree from the University of Cambridge, UK in 1986 and her Ph.D. from the University of Surrey, UK in 1996.

She worked at Westland Helicopters (1982-1987), ERA Technology (1987-1995) and a small software company (1996-2001), before joining the University of Manchester as a Research Associate, and was appointed as a lecturer in 2008. Her research interests are the modelling and control of electrical drive and generator systems for transport and industrial applications, with a particular focus on energy-efficiency. 